\title{
A prospective study on defecation frequency, stool weight, and consistency
}

\author{
Myo-Khin, Thein-Win-Nyunt, S Kyaw-Hla, Thein-Thein-Myint, T D Bolin
}

\begin{abstract}
It has been commonly believed that children in developing countries pass stools that are very different from those of developed countries. A community based study on defecation frequency, stool weight, and consistency was conducted in a cohort of 300 Myanmar (Burmese) children aged 1 to 4 years. Most $(80 \cdot 3 \%)$ children opened their bowels daily and none passed more than three stools a day. The mean (SD) defecation frequency was $6.98(1.94)$ times a week and total stool weight was 596 (221) $\mathrm{g}$ a week. The majority $(61 \%)$ of children passed soft stools. At all ages, there was no significant difference in the defecation frequency, stool weight, and consistency between boys and girls, those on adult style diet and those partially weaned, and between age groups.
\end{abstract}

(Arch Dis Child 1994; 71: 311-314)

Although normal and abnormal bowel habits have been documented in adult populations, there are few systematic studies of the normal bowel habit of preschool age children and few studies on the bowel habits of children from developing countries. Schuster called for more data on normal stools, ${ }^{1}$ and Weaver pointed out that there were only few systematic studies of the normal bowel habit of large populations of healthy children. ${ }^{2}$ There are studies based on clinical history and questionnaires, ${ }^{3-5}$ and hospital based studies on bowel habit in normal infants ${ }^{6-8}$ and in preterm infants. ${ }^{9}$ Community based studies of the frequency, size, and consistency of the stools of 1 to 4 year old children from England ${ }^{10}$ and South Africa ${ }^{11}$ have also been reported.

Although it may be assumed that young infants from developing countries follow the same patterns of stool frequency and consistency as their Western counterparts, the effect of different diet may alter the pattern at an older age. Burkitt and his colleagues, based on their findings in African children, stated that children in developing countries pass stools that reflect a diet of unrefined carbohydrate and low fat content and are very different from those passed by children in Europe. ${ }^{12}$

There is no information on the bowel habit of children from other developing countries where they consume different staple foods from those in Africa or Europe. We therefore carried out a prospective study to determine the bowel habit of a childhood population from Myanmar where the staple diet is based on rice and reported on the defecation frequency, faecal weight, and faecal consistency in relation to gender, age, and diet.

\section{Subjects and methods}

The study was carried out on 300 apparently healthy children between the ages of 1 to 4 years living in a semiurban area of Yangon (Rangoon), Myanmar (Burma). One child from each selected household was recruited for the study. The survey team visited the household to explain the study to the mother and/or guardians of the children. After obtaining consent from the parents/guardians, the age of each child was checked on the birth register and a standard form used to take feeding history, weaning practice, and dietary pattern. Only one child from each household was recruited due to the tedious nature of stool collection, weighing, and the need for close rapport with the family. The study was conducted for six months from December 1991, and each individual study period was seven days.

Preweighed plastic sheets and aluminium pots were distributed to the participating children to collect each stool. A field worker visited the household in the morning and evening. The stool consistency was noted and the stool was weighed using a portable dial-type balance and recorded to the nearest $20 \mathrm{~g}$. A daily record of the type and amount of food eaten by the child was also recorded.

\section{WORKING DEFINITIONS}

The frequency of stool passage was counted only when there was at least one hour since the previous defecation. Defecation frequency was classified as 'less than one' when the child passed stools on alternate days (or) every third, fourth, fifth, sixth, seventh day, 'one', 'two', 'three', etc, for the exact number of times the child defecated. The term modal defecation frequency refers to the frequency observed in a child for more than $50 \%$ of the time during the study period. Stool consistency was classified as 'hard' when the child's stool was discrete in many small lumps, 'semisolid' when pieces of stool were mingling with uniformly matted stool, and 'soft' when it was uniformly matted. The term modal stool consistency means the consistency observed in a child for more than $50 \%$ of the time during the study period.

\section{STATISTICAL ANALYSIS}

Data processing was performed with SPSS (Statistical Package For Social Scientists Ver 3; 
Table 1 Defecation frequency and total stool weight in a cohort of children aged 1 to 4 years of age

\begin{tabular}{|c|c|c|c|c|}
\hline & \multicolumn{4}{|l|}{ Age groups } \\
\hline & $\begin{array}{l}1 \text { Year } \\
(n=86)\end{array}$ & $\begin{array}{l}2 \text { Years } \\
(n=99)\end{array}$ & $\begin{array}{l}3 \text { Years } \\
(n=76)\end{array}$ & $\begin{array}{l}4 \text { Years } \\
(n=39)\end{array}$ \\
\hline $\begin{array}{l}\text { Stool frequency (No/week) } \\
\text { Mean (SD) } \\
95 \% \text { CI }\end{array}$ & $\begin{array}{l}6.74(1.9) \\
6.39 \text { to } 7.21\end{array}$ & $\begin{array}{l}7 \cdot 0(2 \cdot 2) \\
6 \cdot 56 \text { to } 7 \cdot 44\end{array}$ & $\begin{array}{l}6.93(1.7) \\
6.51 \text { to } 7.29\end{array}$ & $\begin{array}{l}6.53(2 \cdot 8) \\
5.59 \text { to } 7 \cdot 40\end{array}$ \\
\hline $\begin{array}{l}\text { Stool weight (g/week) } \\
\text { Mean (SD) } \\
95 \% \text { CI }\end{array}$ & $\begin{array}{l}560(231) \\
510 \text { to } 609\end{array}$ & $\begin{array}{l}579(216) \\
535 \text { to } 622\end{array}$ & $\begin{array}{l}649(181) \\
608 \text { to } 690\end{array}$ & $\begin{array}{l}616(256) \\
533 \text { tc } 699\end{array}$ \\
\hline
\end{tabular}

SPSS Corporation) on a Toshiba T3100e computer. Data were expressed as mean and 95\% confidence interval (CI) and the mean differences calculated using Student's $t$ test; $\mathrm{p}<0.05$ was chosen as a significant level.

\section{ETHICAL CONSIDERATIONS}

The study was approved by the medical ethics committee of the Department of Medical Research, Yangon (Rangoon), Myanmar (Burma).

\section{Results}

Of 300 children recruited 143 were boys and 157 were girls. They were classified into age groups using completed years of age. There were $86(29 \%), 99(33 \%), 76(25 \%)$, and $39(13 \%)$ children in the $1,2,3$, and 4 year age groups respectively. Most $(69 \%, \mathrm{n}=207)$ of the children were weaned and were taking adult food which consisted of rice as the staple food with some meat/fish/chicken and a vegetable soup. Eighty nine children $(29 \cdot 7 \%)$ were still breast fed and four children $(1 \cdot 3 \%)$ were still bottle feeding, but they were also on adult type food consisting mainly of rice, potato, some meat or fish pieces, and peanut oil.

The children passed 2055 stools of which 580 were passed by the 1 year olds, 693 by the 2 year olds, 527 by the 3 year olds, and 255 by the 4 year olds. The mean (SD) weekly defecation frequency for the group was $6 \cdot 85(2 \cdot 1)$. The boys did not significantly differ from the girls $(6.98(1.94) v 6.73(2 \cdot 24)$ stools) and this pattern was seen consistently in all age groups. Table 1 shows mean defecation frequencies and $95 \%$ CI for different age groups. Most children (80.3\%) opened their bowels every day and some $(10 \%)$ twice a day. No age specific pattern was observed and the general stool frequency for all age groups

Table 2 Defecation frequency and consistency of stools passed by a cohort of children aged 1 and 4 years. Values are number (\%)

\begin{tabular}{lcccr}
\hline \multicolumn{5}{c}{ Age groups } \\
\cline { 2 - 5 } & $\begin{array}{l}1 \text { Year } \\
(n=86)\end{array}$ & $\begin{array}{l}2 \text { Years } \\
(n=99)\end{array}$ & $\begin{array}{l}3 \text { Years } \\
(n=76)\end{array}$ & $\begin{array}{c}4 \text { Years } \\
(n=39)\end{array}$ \\
\hline General frequency (motions/day) & $7(8 \cdot 2)$ & $8(8 \cdot 1)$ & $4(5 \cdot 3)$ & $7(17 \cdot 9)$ \\
$<1$ & $74(86 \cdot 1)$ & $75(75 \cdot 8)$ & $63(82 \cdot 9)$ & $29(74 \cdot 4)$ \\
1 & $5(16 \cdot 7)$ & $14(14 \cdot 1)$ & $9(11 \cdot 8)$ & $2(5 \cdot 1)$ \\
2 & - & $2(2 \cdot 0)$ & - & $1(2 \cdot 6)$ \\
3 & $48(55 \cdot 8)$ & $64(64 \cdot 7)$ & $46(60 \cdot 5)$ & $25(64 \cdot 1)$ \\
General consistency & $29(33 \cdot 7)$ & $21(21 \cdot 2)$ & $21(27 \cdot 7)$ & $9(23 \cdot 1)$ \\
Soft & $9(10 \cdot 5)$ & $14(14 \cdot 1)$ & $9(11 \cdot 8)$ & $5(12 \cdot 8)$ \\
Hard & & & & \\
Semisolid & & &
\end{tabular}

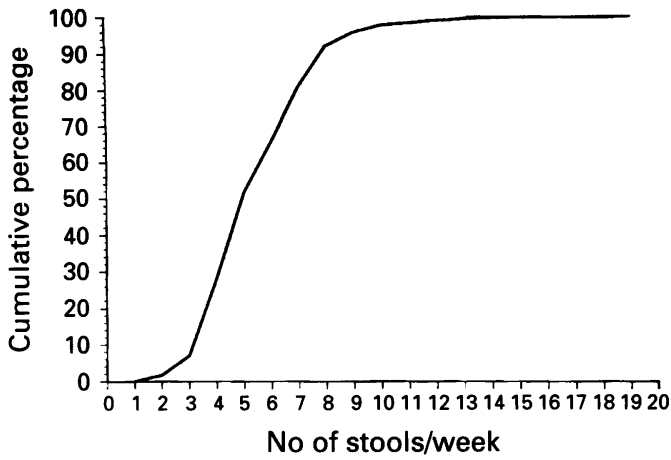

Figure 1 Cumulative frequency of number of stools/week in a cohort of 300 children aged 1 to 4 years.

is shown in table 2. A few children $(8 \cdot 7 \%)$ opened their bowels less than once a day and only one child in the 4 year age group and two children in the 2 year age group opened their bowels three times a day. None of the children passed stools more than three times in any day of the study. Eighty per cent of the children passed fewer than eight stools a week. The cumulative frequency percentage of children for all age groups are shown in fig 1.

A total of $178.74 \mathrm{~kg}$ of stools were passed by all children. The mean (SD) weekly total stool weight for all children was 596 (221) g. Again, there was no significant difference between the boys and the girls (606 (213) v 586 (229) g) and this applied in all age groups. Table 1 shows the total stool weight passed in one week according to age. Although the 1 year old children passed the smallest amount of stool, no significant differences were observed between the different age groups. However, a weak correlation $(r=0 \cdot 13)$ was observed between total stool weight/week and age (fig 2) as would be expected.

At all ages, most children passed soft stools: $186(61 \%)$ soft, $80(27 \%)$ hard, and 37 children $(12 \%)$ passed semisolid stools. This distribution was found in all age groups (table 2).

A relationship to diet was not observed. The mean total stool weight of the children who were weaned and taking adult food was $614 \mathrm{~g}$ (95\% CI 585 to 644 ) and was not different from that of children with mixed feeding (554; $95 \%$ CI 506 to 602 ).

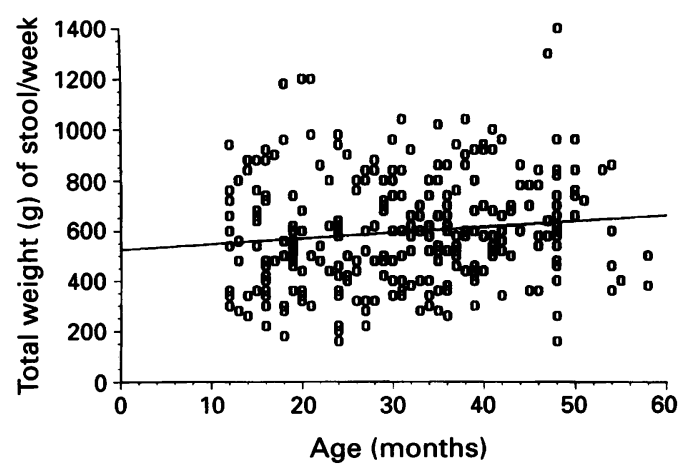

Figure 2 Relationship between total stool weight/week and the child's age in months $(\mathrm{r}=0.125 ; p<0.029)$. 


\section{Discussion}

Data on stool size and consistency are difficult to obtain except in physiological studies of small groups investigated for nutritional or medicinal purposes. ${ }^{2}$ The present study documents the total stool weight of 300 children between the ages of 1 to 4 years from a developing country in Asia. The stools were weighed and their frequencies recorded at home. Previous studies depended on the use of proxy measurements to obtain the consistency and weight of the stools. Weaver and Steiner used questionnaires and a set of plasticine stools of different volumes to help mothers judge the size of their children's stools. ${ }^{10}$ The size of the stools were of a grape $(5 \mathrm{ml})$, a small sausage $(25 \mathrm{ml})$, and a large sausage $(40 \mathrm{ml})$. Walker and Walker in their study of bowel behaviour in 275 children used similar pictures. ${ }^{11}$ Thus the present study had an advantage to recording actual measurements. A seven day study period was also chosen to minimise the variation in bowel habit reported by other workers.

The consistency scale used in the present study is of three categories (soft, hard, and semisolid) and similar to that of other studies. ${ }^{1011}$ Studies on bowel function in adults have used a wider scale for stool consistency. ${ }^{1314}$ We did not believe that using a wide scale had any advantage.

Our study has its limitations. Individual stools were not weighed. Stools were weighed either in the morning or in the evening. In a field situation with a portable weighing scale, weighing each stool whenever a child defecates was not practical. We felt that using a seven day study period with twice daily measurement of stools was adequate.

Most $(90.3 \%)$ of the children defecated once or twice a day. This is consistent with the findings in British children. ${ }^{10}$ However, studies from South Africa reported much higher daily frequencies. In a household survey, $44 \%$ of children had three or more stools a day. ${ }^{12}$ Walker and Walker studied South African children aged 1 to 4 years from rural and urban areas and reported that 9 to $14 \%$ of the children defecated three or more times a day and that black children passed stools more frequently than white children. ${ }^{11}$ Although a decline in daily mean frequency with age has been reported, ${ }^{10}$ we did not find this.

The upper values of defecation frequency in a population is important in defining diarrhoeal and non-diarrhoeal states. From hospital records dating back to $1910,{ }^{15}$ acute childhood diarrhoea has been shown to be a major health problem in Myanmar. Diarrhoea is usually defined as watery stools or passing three or more soft stools which take the shape of the container into which they are passed. The findings of our study show only $1 \%$ of children with three motions a day, and none with more than three a day, supporting the suitability of the definition of diarrhoea for our population.

Most children in our study passed soft stools. This is consistent with the findings in studies from England ${ }^{10}$ and South Africa. ${ }^{12}$ In the present study, the mean weekly total stool weight was $596 \mathrm{~g}$ and equates to $85 \mathrm{~g}$ a day. It is three times less than that of rural African children (275 g), ${ }^{16}$ but comparable with that of African children (age 10-12 years) having a partly Westernised diet whose daily stool weight was $75 \mathrm{~g}^{12}$ and Canadian children aged 3 to 13 years with $78 \mathrm{~g} /$ day. ${ }^{13}$

Recently, women's bowel function has been shown to be different from that of men. ${ }^{14}$ Weaver found no significant difference in bowel function in relation to frequency, consistency, and stool weight between boys and girls and our findings agree with this study. ${ }^{10}$ The difference in gender may become apparent at an older age where other factors such as hormones, diet, and exercise may change. An effect of diet was not observed in our study.

By describing the normal range of stool frequency, weight, and consistency of a childhood population with a rice based staple diet our findings contribute towards better understanding of constipation and diarrhoea in childhood. They also help in developing definitions to be used in clinical, laboratory, and field studies.

1 Schuster MM. Chronic constipation in children: the need for hard data about normal stools. $f$ Pediatr Gastroenterol Nutr 1984; 3: 336-73.

2 Weaver LT. Bowel habit from birth to old age. $\mathcal{f}$ Pediatr Gastroenterol Nutr 1988; 7: 637-40.

3 Colon AR, Jacob LJ. Defecation patterns in American infants and children. Clin Pediatr (Phila) 1977; 16: 999-1000.

4 Taylor I. A survey of normal bowel habit. Br $\mathcal{f}$ Clin Pract 1975; 29: 289-91.

5 Connell AM, Hilton C, Irvine G, Lennard-Jones JE, Misiewicz JJ. Variation of bowel habit in two population samples. BMF 1965; ii: 1095-9.

6 Nyhan WL. Stool frequency of normal infants in the first week of life. Pediatrics 1952; 10: 414-25.

7 Lemoh JN, Brooke OG. Frequency and weight of normal stools in infancy. Arch Dis Child 1979; 54: 719-20.

8 Weaver LT, Ewing G, Taylor LC. The bowel habit of milkfed infants. F Pediatr Gastroenterol Nutr 1988; 7: 568-71.

9 Weaver LT, Lucas A. Development of bowel habit in preterm infants. Arch Dis Child 1993; 68: 317-20.

10 Weaver LT, Steiner H. The bowel habit of young children. Arch Dis Child 1984; 59: 649-52.

11 Walker ARP, Walker BF. Bowel behaviour in young black and white children. Arch Dis Child 1985; 60: 967-70.

12 Burkitt D, Morley D, Walker A. Dietary fibre in under- and over-nutrition in childhood. Arch Dis Child 1980; 55: 803-7.

13 Davies GJ, Crowder M, Reid B, Dickerson JWT. Bowel function measurements of individuals with different eating patterns. Gut 1986; 27: 164-9.

14 Heaton KW, Radvan J, Cripps H, Mountford RA, Braddon FEM, Hughes AO. Defecation frequency and timing, and stool form in the general population: a prospective study. Gut 1992; 33: 818-24.

15 Thaung U. Epidemiology of acute diarrhoea in childhood. Proceedings of the research seminar on acute diarrhoea in childhood. Rangoon, 27 February 1982. Rangoon (Yangon): hood. Rangoon, 27 February 1982. Rango

16 Burkitt DP, Walker ARP, Painter NS. Effect of dietary fibre on stools and transit times, and its role in the causation of disease. Lancet 1972; ii: 1408-11.

\section{Commentary}

Myo-Khin et al have shown that the defecation frequency of Burmese children differs little from that of English children, even though they eat a very different diet. This suggests that in early life, although diet may affect stool size, it has little effect on frequency of bowel actions. Their paper also provides data from which a clearer definition of diarrhoea can be formulated.

The authors are to be congratulated on responding, after almost 20 years, to Burkitt's 